\title{
Thy-1 interaction with Fas in lipid rafts regulates fibroblast apoptosis and lung injury resolution
}

\author{
Xiaoqiu Liu', Simon S Wong ${ }^{2}$, Carmen A Taype ${ }^{3}$, Jeeyeon Kim, Tzu-Pin Shentu², Celia R Espinoza², J Cameron Finley ${ }^{5}$, \\ John E Bradley ${ }^{6}$, Brian P Head ${ }^{5,7}$, Hemal H Patel ${ }^{5,7}$, Emma J Mah ${ }^{8}$ and James S Hagood ${ }^{2,9}$
}

Thy-1-negative lung fibroblasts are resistant to apoptosis. The mechanisms governing this process and its relevance to fibrotic remodeling remain poorly understood. By using either sorted or transfected lung fibroblasts, we found that Thy- 1 expression is associated with downregulation of anti-apoptotic molecules $\mathrm{BCl}-2$ and $\mathrm{BCl}-\mathrm{xL}$, as well as increased levels of cleaved caspase-9. Addition of rhFasL and staurosporine, well-known apoptosis inducers, caused significantly increased cleaved caspase-3, -8, and PARP in Thy-1-transfected cells. Furthermore, rhFasL induced Fas translocation into lipid rafts and its colocalization with Thy-1. These in vitro results indicate that Thy-1, in a manner dependent upon its glycophosphatidylinositol anchor and lipid raft localization, regulates apoptosis in lung fibroblasts via Fas-, Bcl-, and caspase-dependent pathways. In vivo, Thy-1 deficient $\left(\right.$ Thy $1^{-1-}$ ) mice displayed persistence of myofibroblasts in the resolution phase of bleomycin-induced fibrosis, associated with accumulation of collagen and failure of lung fibrosis resolution. Apoptosis of myofibroblasts is decreased in $T h y 1^{-1-}$ mice in the resolution phase. Collectively, these findings provide new evidence regarding the role and mechanisms of Thy- 1 in initiating myofibroblast apoptosis that heralds the termination of the reparative response to bleomycin-induced lung injury. Understanding the mechanisms regulating fibroblast survival/apoptosis should lead to novel therapeutic interventions for lung fibrosis.

Laboratory Investigation (2017) 97, 256-267; doi:10.1038/labinvest.2016.145; published online 6 February 2017

Myofibroblast apoptosis is a fundamental mechanism during normal wound healing. During the resolution phase, this cellspecific apoptosis is triggered mainly by the extrinsic pathway via Fas receptor (Apo-1/CD95) trimerization, Bcl protein downregulation, and subsequent caspase cascade activation. ${ }^{1}$ Programmed cell death is characterized by marked changes in cellular morphology, including the appearance of membranebound apoptotic bodies, internucleosomal DNA fragmentation, as well as by cleavage of poly(ADP-ribose) polymerase (PARP). ${ }^{2}$ However, fibroblasts insensitive to apoptotic stimuli can induce accumulation of apoptosis-resistant myofibroblasts, a hallmark of pathological fibrosis. ${ }^{3-6}$

Mechanisms underlying the resolution of pulmonary fibrosis have been recently reviewed. ${ }^{7}$ In recent years, increasing attention has been paid to understanding the apoptotic alterations leading to non-resolving and progressive fibrotic remodeling with the intention of developing targeted therapies for lung fibrosis. Thus, it was found that increased expression of Fas, a cell surface death receptor in the tumor necrosis factor receptor superfamily, is necessary to directly sensitize apoptosis-resistant fibroblasts. ${ }^{8}$ Furthermore, a recent study showed that tumor necrosis factor- $\alpha$ is an inducer of apoptosis that mediates lung fibrosis resolution..$^{9}$ In addition, it has been described that functional FasL(+) immune cells could promote resolution of lung fibrosis, ${ }^{10}$ indicating that factors that interfere with the Fas/FasL interaction between $\mathrm{T}$ cells and myofibroblasts could abrogate immune surveillance during fibrosis. Taken together, these recent emerging studies strongly indicate that both preservation of apoptosis susceptibility in fibroblasts, and apoptosis induction in apoptosis-resistant myofibroblasts have significant therapeutic potential.

Thy-1/CD90 is a glycophosphatidylinositol (GPI)-anchored cell surface glycoprotein that modulates apoptosis signaling

\footnotetext{
'Respiratory Department, Second Hospital of Jilin University, Changchun, China; ${ }^{2}$ Division of Respiratory Medicine, Department of Pediatrics, University of California San Diego, San Diego, CA, USA; ${ }^{3}$ Division of Pulmonary and Critical Care Medicine, Department of Medicine, University of California San Diego, La Jolla, CA, USA; ${ }^{4}$ Department of Pediatrics, Stanford University, Palo Alto, CA, USA; ${ }^{5}$ Department of Anesthesiology, UCSD, San Diego, CA, USA; ${ }^{6}$ epartment of Microbiology, University of Alabama-Birmingham, Birmingham, AL, USA; ${ }^{7}$ VA San Diego Healthcare System, San Diego, CA, USA; ${ }^{8}$ Department of Chemical and Biochemical Engineering, University of California_Irvine, Irvine, CA, USA and ${ }^{9}$ Division of Respiratory Medicine, Rady Children's Hospital of San Diego, San Diego, CA, USA

Correspondence: Dr JS Hagood, MD, Division of Respiratory Medicine, Department of Pediatrics, University of California San Diego (UCSD), 9500 Gilman Dr. MC 0731, San Diego, CA 92093-0731, USA.

E-mail: jhagood@ucsd.edu
}

Received 12 September 2015; revised 23 November 2016; accepted 14 December 2016 
pathways in a variety of cell types, including hepatic cells, ${ }^{11}$ glomerular mesangial cells, ${ }^{12}$ and dermal fibroblasts. ${ }^{13}$ It has become evident that Thy-1-mediated apoptotic mechanisms are cell type dependent. ${ }^{14}$ For example, Thy- 1 must aggregate to signal thymocyte apoptosis, whereas apoptosis of Thy-1(+) thymoma cells occurs through a mechanism requiring new transcription. We have found that Thy-1(-) myofibroblasts are resistant to apoptosis in response to collagen gel contraction. ${ }^{15,16}$ Furthermore, Thy-1-deficient $\left(T h y 1^{-/-}\right)$ mice develop more severe lung fibrosis than wild-type (Wt) mice, associated with the accumulation of lung myofibroblasts. ${ }^{17}$ However, the molecular mechanisms by which Thy-1 modulates fibroblast apoptosis and Thy-1's importance during lung tissue remodeling remain to be characterized.

In this study, we evaluated the mechanisms whereby Thy-1 modulates apoptosis-related intracellular signaling pathways, and the role of membrane microdomain localization via the Thy-1-specifc GPI anchor in this process. We also studied the in vivo effect of Thy-1 during myofibroblast apoptosis by using Thy 1 null mice. Our data demonstrate that Thy-1 surface expression is necessary and sufficient to promote apoptosis in lung myofibroblasts.

\section{MATERIALS AND METHODS}

\section{Animals and Bleomycin-Induced Fibrosis}

Adult Thy-1 knock-out $\left(\right.$ Thy $\left.1^{-/-}\right),{ }^{18}$ a kind gift of Kevin Kelley, Mt. Sinai School of Medicine, and Wt mice on C57BL/ 6 background (both genders) were utilized for this study. All mice were housed in the Association for Accreditation and Assessment of Laboratory Animal Cares-approved animal facility at the University of California San Diego, School of Medicine. To generate pulmonary injury and fibrosis, mice anesthetized (i.p.) with ketamine $(80 \mathrm{mg} / \mathrm{kg}) /$ xylazine $(10 \mathrm{mg} / \mathrm{kg})$ were orotracheally instilled with bleomycin $(5 \mathrm{U} / \mathrm{kg} \mathrm{BW}$, Tecoland Corporation) dissolved in sterile saline $(100 \mu \mathrm{l})$ via MicroSprayer (MS-IA-1C, Penn-Century) or sterile saline for controls.

\section{Histopathological Evaluation}

At each time point after bleomycin instillation, lungs were fixed $\left(10 \%\right.$ formalin at a constant pressure of $\left.20 \mathrm{~cm} \mathrm{H}_{2} \mathrm{O}\right)$, and paraffin embedded. Five micrometer-thick sagittal sections of all lobes of fixed lungs were cut and subsequently stained for H\&E and Masson's trichrome staining to evaluate the lung fibrotic response.

\section{Detection of Myofibroblast Apoptosis In Vivo}

Co-localization of cleaved caspase-3, an apoptosis marker, and $\alpha$-SMA, a myofibroblast marker, was conducted to confirm myofibroblast apoptosis by immunofluorescence. Five micrometer-thick OTC-embedded samples were cut and then fixed using $4 \%$ formaldehyde, permeabilized in $0.2 \%$ Triton X-100 for $5 \mathrm{~min}$, and blocked with 10\% normal goat serum. Primary antibodies for alpha smooth-muscle actin (aSMA; 1:200; Ab21027, Abcam), cleaved caspase-3 (1:200;
\#9661, Cell Signaling) along with AlexaFluor-labeled secondary antibodies (Life Technologies) were used. Images were acquired at $\times 20$ (Plan-fluor, 0.5 N.A.) or $\times 60$ (Plan-apochromat, 1.4 N.A.) magnification with a fluorescence microscope. Myofibroblasts expressing high levels of aSMA and/or cleaved caspase-3 were counted in six different random high-powered fields of the lung in each mouse, 5-6 mice per group.

\section{Cell Culture}

Rat fetal lung fibroblasts, which are entirely Thy-1 negative (RFL6; American Type Culture Collection, Manassas, VA), were cultured in Ham's F12 K nutrient mixture (F-12K) media containing $10 \%$ FBS and $1 \%$ penicillin/streptomycin. Mouse embryonic fibroblasts (MEFs) were isolated from C57BL/6 mice and sorted for Thy-1 expression using FITC-labeled Thy-1.2-specific antibodies as previously described. ${ }^{19}$ Sorted MEFs were cultured in Dulbecco's modified Eagle's medium (DMEM; Cellgro, Manassas, VA) supplemented with $10 \% \mathrm{FBS}$, in a humidified incubator with $5 \% \mathrm{CO}_{2}$. Two different batches of sorted Thy- 1 subpopulations of MEFs were used in this study and yielded similar results.

\section{Cell Transfection}

RFL-6 cells were stably transfected with the mammalian expression vector pcDNA3.1 $\mathrm{Zeo}^{+}$containing the full-length murine Thy-1.2 (CD90.2) cDNA (RFL-6 Thy- $1^{+}$) or empty vector (RFL-6 Thy- $1^{-}$) as previously described. ${ }^{20}$ The expression of Thy-1 at levels similar to those in naturally occurring Thy-1(+) fibroblasts was confirmed by FACS analysis. ${ }^{9,21}$ For Thy-1 GPI anchor studies, RFL-6 cells were transfected with Wt human Thy-1 (hThy-1) or human Thy1-hinge TR3, a chimeric construct in which the GPI anchor of hThy-1 was replaced with the GPI addition sequence of TRAIL receptor $3 .^{22}$ Absence of Thy-1 protein in untransfected and empty vector-transfected RFL-6, and appropriate levels of expression in Thy-1 - and Thy- 1 mutant-transfected cells have been demonstrated previously. ${ }^{22,23}$

\section{Antibodies and Reagents for In Vitro Assays}

Soluble human recombinant FasL (rhFasL) (Kamiya Biomedical Company, Seattle, WA); staurosporine (ACROS Organics, Pittsburgh, PA); caspase-8 inhibitor II (EMD Millipore, Billerica, MA); protein G-agarose (Roche Diagnostics, Indianapolis, IN); Z-FA-FMK (negative control for caspase inhibitors), FITC Rat anti-mouse CD90.2, FITC Rat IgG1, $\kappa$ isotype, Annexin V apoptosis detection kit, and APO-Direct kit (BD Pharmingen, San Jose, CA); rabbit anti-PARP antibody, rabbit anti-caspase-3 antibody, rabbit anti-cleaved caspase-3 antibody, rabbit anti-cleaved caspase-8 antibody, and rabbit anti-cleaved caspase-9 antibody (Cell Signaling Technologies, Danvers, MA); anti-mouse Thy-1 (AbD Serotec, Oxfordshire, UK), and anti- $\alpha$ actin polyclonal antibody (Santa Cruz Biotechnology, Dallas, TX). 


\section{Cell Treatments}

Cells were grown to $80 \%$ confluence in culture dishes and made quiescent in culture media supplemented with $0.4 \%$ FBS for $24 \mathrm{~h}$. Fresh $0.4 \%$ FBS culture media was added before stimulation with indicated concentrations of rhFasL or staurosporine for $16 \mathrm{~h}$. For caspase- 8 inhibition experiments, Thy-1(+) RFL-6 cells were pretreated with or without caspase-8-specific inhibitor for $30 \mathrm{~min}$ followed by treatment with rhFasL or staurosporine.

\section{Apoptosis Assay}

RFL-6 Thy-1(+) and RFL-6 Thy-1(-) cells were rendered quiescent in culture media supplemented with $0.4 \%$ FBS for $24 \mathrm{~h}$, then treated with the indicated concentrations of rhFasL for $16 \mathrm{~h}$. After treatment, adherent and non-adherent cells were collected by centrifugation and stained with Annexin V and PI, resuspended in $500 \mu \mathrm{l}$ binding buffer and analyzed by flow cytometry.

\section{DNA Fragmentation and TUNEL Assays}

The APO-Direct assay kit was used as per the manufacturer's protocol. Briefly, cells were cultured at a density of $0.4 \times 10^{6}$ cells in six-well dishes and treated with $50 \mathrm{ng} / \mathrm{ml}$ of rhFasL for $16 \mathrm{~h}$. Labeled cells were counted in a flow cytometer and analyzed using Cell Quest software (San Jose, CA).

\section{Immunoblotting}

At the end of respective cell treatments, cells were washed with cold PBS twice and lysed with $1 \times$ SDS reducing sample buffer containing protease inhibitors. Cell lysates were collected in siliconized tubes and sonicated for $20 \mathrm{~s}$ three times. After centrifugation at $4000 \mathrm{~g}$ for $1 \mathrm{~min}$ at $4{ }^{\circ} \mathrm{C}$, cell lysates were stored at $-80^{\circ} \mathrm{C}$ in aliquots until use. Equal volumes of cell lysate were loaded on SDS-PAGE gels under reducing conditions. After electrophoresis, proteins were transferred to PVDF membranes at $100 \mathrm{~V}$ for $1 \mathrm{~h}$ at $4{ }^{\circ} \mathrm{C}$. To block nonspecific protein binding sites, the membranes were incubated with 5\% non-fat milk in Tris-buffered saline/Tween-20 (0.1\%) for $1 \mathrm{~h}$ at room temperature. Membranes were incubated with primary antibodies in Tris-buffered saline/Tween-20 (0.1\%) overnight. Membranes were washed extensively before being incubated with appropriate peroxidase-conjugated secondary antibodies for $1 \mathrm{~h}$ at room temperature. Immunodetection was performed by chemiluminescence.

\section{Isolation of Lipid Rafts and Immunoprecipitation}

Membrane fractionation and immunoprecipitation were performed as previously described. ${ }^{24}$ Proteins from membrane fractionation were analyzed by immunoblotting. For immunoprecipitation, $10 \mathrm{~cm}$ plates of RFL- 6 Thy- $1(+)$ and RFL- 6 Thy-1(-) cells were washed twice with cold PBS, scraped in $1 \mathrm{ml}$ of modified Lysis buffer $(50 \mathrm{mM}$ Tris- $\mathrm{HCl}, \mathrm{pH} 7.5$, $10 \mathrm{mM} 150 \mathrm{mM} \mathrm{NaCl}, 1 \mathrm{mM}$ EGTA, plus mammalian protease inhibitor cocktail) and homogenized in a dounce homogenizer. Precleared samples were incubated with primary antibody for Fas for $1-3 \mathrm{~h}$ then precipitated by incubating with protein G-agarose overnight. Pellets were washed once in lysis buffer followed by washes in buffers $1(50 \mathrm{mM}$ Tris- $\mathrm{HCl}, \mathrm{pH}$ $7.5,500 \mathrm{mM} \mathrm{NaCl}$, and $0.2 \%$ Triton X-100) and $2(10 \mathrm{mM}$ Tris- $\mathrm{HCl}, \mathrm{pH} 7.5$, and $0.2 \%$ Triton X-100). Immunoprecipitated proteins were analyzed by immunoblotting.

\section{Immunofluorescence Staining}

RFL-6 Thy-1(+) cells were cultured on coverslips in 12-well plates, grown to $70 \%$ confluence, made quiescent with culture media supplemented with $0.4 \%$ FBS for $24 \mathrm{~h}$, and stimulated with $50 \mathrm{ng} / \mathrm{ml} \mathrm{rhFasL}$ for $16 \mathrm{~h}$. Cells were washed with $2 \times$ serum-free medium and incubated with FITC-Rat anti-Thy1.2 (1:20) or Rat IgG1 $\kappa$ isotype as control. Then cells were fixed with $3.7 \%$ formaldehyde for $15 \mathrm{~min}$, washed with sterile PBS, blocked in 5\% normal goat serum, and incubated with mouse IgM or mouse anti-Fas (1:50) followed by Texas Red $\mathrm{X}$-conjugated secondary antibody (1:40). Coverslips were washed and mounted using Gelvatol mounting medium ${ }^{25}$ on glass microscope slides and examined with an Olympus FV 1000 Spectral Confocal fluorescence microscope. Images were acquired with a digital camera and analyzed with velocity analysis software (PerkinElmer, Waltham, MA).

\section{Data Analysis and Statistics}

Data are presented as the mean \pm s.e.m. and statistical differences in the mean values for animal $(n=10)$ and cell culture studies $(n=3)$ were determined by using a one-way ANOVA test with posthoc analysis using Tukey's multiple comparison test using GraphPad Prism 4.0.

\section{RESULTS}

\section{Thy-1 Expression Promotes Fibroblast Susceptibility to Apoptosis}

The ability of Thy- 1 to promote apoptosis was assessed in RFL-6 Thy-1(+) and RFL-6 Thy-1(-) cells. At $10 \mathrm{ng} / \mathrm{ml}$, rhFasL was insufficient to induce apoptosis in either cell type. However, an increased number of apoptotic cells was observed in RFL-6 Thy-1(+) cells in response to 50 and $100 \mathrm{ng} / \mathrm{ml}$ rhFasL (from $\sim 15$ to $35 \%$ as demonstrated by Annexin V/PI assay). The number of apoptotic cells remained unchanged in RFL-6 Thy-1(- ) cells at the same concentrations of rhFasL (Figure 1a). To verify Annexin V/PI data, we measured apoptosis using a terminal nucleotidyl transferasemediated nick end labeling assay for DNA fragmentation, an irreversible event that commits the cell to die, using the APODIRECT Kit, in identically treated cells. Findings are similar to those from the Annexin V assay (Figure 1b). These results indicate that Thy- 1 can promote apoptosis in fibroblasts.

\section{Thy-1 Expression Increases the Activation of Caspase-3 and $\mathbf{- 8}$}

To understand the mechanisms by which Thy-1 promotes apoptosis in fibroblats, RFL-6 Thy-1(+) and RFL-6 Thy-1(- ) cells were treated with the indicated concentrations of rhFasL 
a

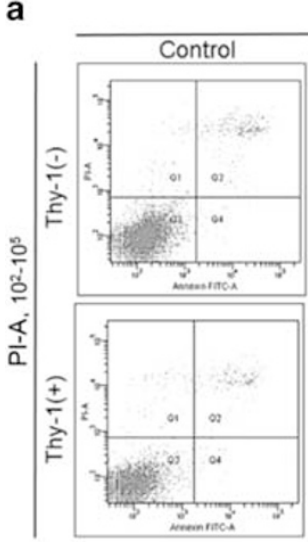

Annexin FITC-A, $10^{2}-10^{5}$ $50 \mathrm{ng} / \mathrm{mL} \mathrm{rh}$ Fas L

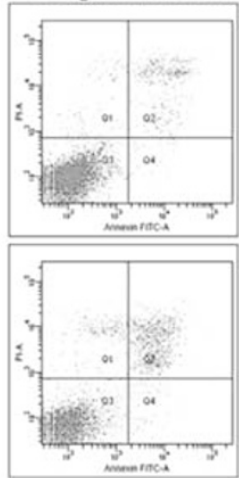

b

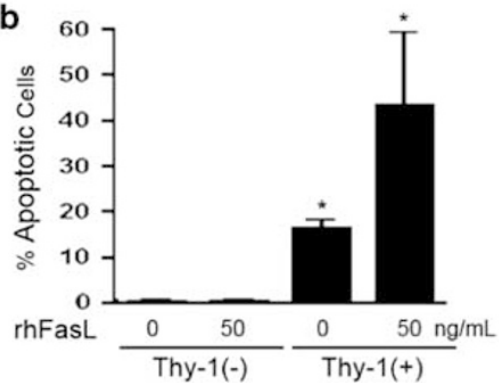

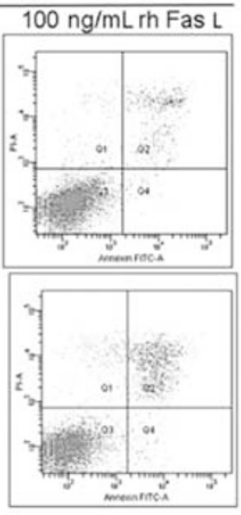

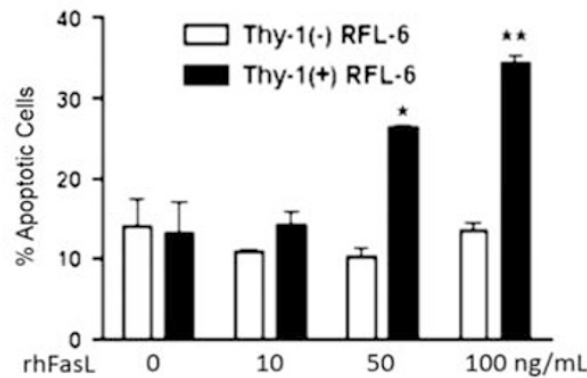

Figure 1 Thy-1 expression promotes fibroblast susceptibility to apoptosis. (a) RFL-6 Thy-1(-) and Thy-1(+) fibroblasts were treated with the indicated concentrations of rhFasL for $16 \mathrm{~h}$, and then cells were collected and stained with Annexin V and PI and apoptosis quantified by flow cytometry. Results are representative of three independent experiments. Upper panels: dot plots of FACS analysis with FITC-Annexin V and PI. The lower-left quadrants of the dot plot panels represent live cells (Annexin $\mathrm{V}-/ \mathrm{PI}-$ ); the lower-right quadrants of the panels quadrants represent early apoptotic cells (Annexin $\mathrm{V}+/ \mathrm{PI}-$ ); the upper-right quadrants of the panels quadrants represent later apoptotic cells (Annexin V+/PI+). Lower panel shows a quantitative representation of the flow cytograms. Each bar represents the mean \pm s.e.m. of early + late apoptosis for at least three experiments. ${ }^{*}$ Denotes $P<0.0001$ compared with controls. (b) Effect of Thy-1 on apoptosis in Thy-1(-) and Thy-1(+) fibroblasts. Cell treatments are the same as above. After treatment, cells were stained with FITC-dUTP, terminal nucleotidyl transferase-mediated nick end labeling assay. The growing cells were treated with rhFasL for $16 \mathrm{~h}$ and the extent of apoptosis was assessed by APO-Direct assay kit. The analyses were done using Cell Quest software; bar represents the mean \pm s.e.m. of at least three experiments. ${ }^{*} P<0.0001$ compared with controls.

for $16 \mathrm{~h}$, and then processed for immunoblotting. As shown in Figure 2a, cleavage of caspase-3 was not detected in untreated and $50 \mathrm{ng} / \mathrm{ml}$ rhFasL-treated RFL-6 Thy-1( - ) cells. In RFL-6 Thy-1(+) cells, there was a significant increase in cleavage of caspase-3 (two small $\sim 19$ and $17 \mathrm{kDa}$ fragments) in response to 50 and $100 \mathrm{ng} / \mathrm{ml} \mathrm{rhFasL}$. Treatment with staurosporine resulted in increased cleavage of caspase- 3 in Thy-1(+) cells (Figure $2 \mathrm{a}$, lower panel). To further confirm this result, sorted Thy-1(+) and Thy-1(-) MEF cells were treated with rhFasL or staurosporine, and cleavage of caspase3 and -8 was assessed. We found that Thy- 1 expression was associated with increased levels of cleaved caspase- 3 and -8 in Thy-1(+) MEFs (Figure 2b). Our results suggest that Thy-1 promotes the activation of the apoptotic extrinsic pathway.

\section{Inhibition of Caspase-8 Decreases the Cleavage of Caspase- 3 and Decreases the Susceptibility to Apoptosis Induced by rhFasL in RFL-6 Thy-1(+) Cells}

Thy-1 expression at the cell surface seems to be enough to promote apoptosis susceptibility in fibroblasts via the extrinsic pathway. To further confirm the participation of caspase- 8 activation in the apoptotic process, RFL- 6 Thy-1(+) cells were pretreated with different concentrations of a specific caspase- 8 inhibitor for $30 \mathrm{~min}$ followed by $50 \mathrm{ng} / \mathrm{ml}$ rhFasL treatment for $16 \mathrm{~h}$ (Figure 3a). Pretreatment with caspase- 8 inhibitor inhibited rhFasL-induced activation of caspase-3 in RFL-6 Thy-1(+) cells in a dose-dependent manner. In addition, RFL- 6 Thy-1(+) cells were pretreated with $20 \mu \mathrm{M}$ of caspase- 8 inhibitor negative control or caspase8 inhibitor for $30 \mathrm{~min}$ followed by $50 \mathrm{ng} / \mathrm{ml} \mathrm{rhFasL}$ treatment for $16 \mathrm{~h}$. Caspase- 8 inhibitor effectively reduced the basal level of apoptosis in untreated cells, and abolished rhFasL-induced apoptosis (Figure 3b).

Thy-1 Inhibits Expression of the Anti-Apoptotic Proteins Bcl-2 and Bcl-xL and Promotes Mitochondrial PathwayMediated Apoptosis Indicated by Cleavage of Caspase-9 We next wanted to assess whether Thy-1 promotes apoptosis via the intrinsic pathway as well. As showed in Figure 4a, Thy-1 expression results in significant decrease in the basal expression levels of $\mathrm{Bcl}-2$ and $\mathrm{Bcl}-\mathrm{xL}$. In response to staurosporine treatment, Thy-1 expression leads to 
a

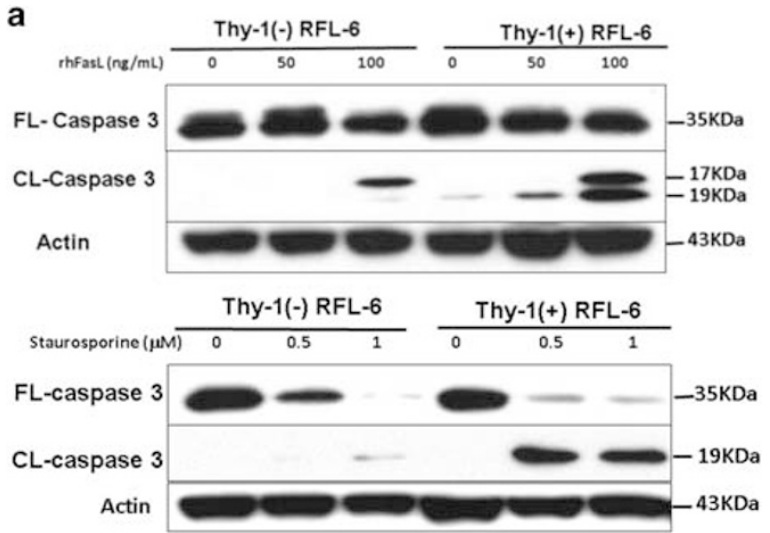

b

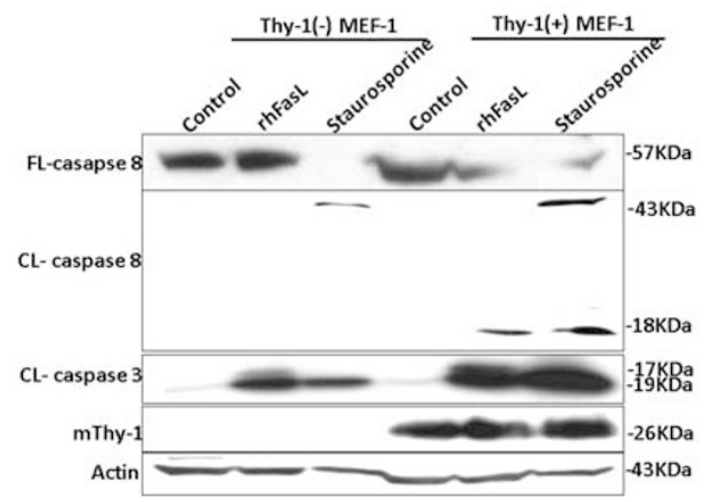

Figure 2 The effect of Thy- 1 expression on the activation of caspase- 3 and -8 in response to apoptosis inducers. (a) Upper panel: Thy-1(-) and (+) RFL6 cells were treated with the indicated concentrations of rhFasL for $16 \mathrm{~h}$. Lower panel: Thy-1(-) and (+) RFL6 cells were treated with the indicated concentrations of staurosporine. Cell lysates were subjected to western blot analysis using cleaved caspase 3 and -8 antibody. Procaspase-3 (full length or FL-caspase-3) and cleaved caspase-3 (CL-caspase-3) expressions are representative of three independent experiments. The cleaved caspase- 3 rabbit mAb detects endogenous levels of the large fragment $(17 / 19 \mathrm{kDa})$ of activated caspase-3. (b) Sorted Thy-1(-) and Thy-1(+) MEF were rendered quiescent and then treated with the $50 \mathrm{ng} / \mathrm{ml}$ rhFasL and $1 \mu \mathrm{M}$ staurosporine for $16 \mathrm{~h}$, and then cells were collected and analyzed by western blots for caspase activation. Pictures are representative of three independent experiments. $\beta$-actin is used as internal control.

significantly greater cleaved caspase-9 than in untreated control samples (Figure $4 \mathrm{~b}$ ). To define whether the activation of caspase- 9 is caspase- 8 dependent, Thy- $1(+)$ MEF cells were pretreated with caspase- 8 inhibitor, and cell lysates were analyzed for cleaved caspase- 9 as shown in Figure 4c. The results showed that caspase- 8 inhibition does not alter caspase-9 activation. All together, these data imply that Thy- 1 is able to independently activate the extrinsic and intrinsic apoptotic pathways in fibroblasts.

\section{PARP Cleavage in Response to rhFasL and Staurosporine-Induced Apoptosis}

PARP is a well-known substrate for cleaved caspase-3 during apoptosis. To prove the activation of caspase- 3 in cells
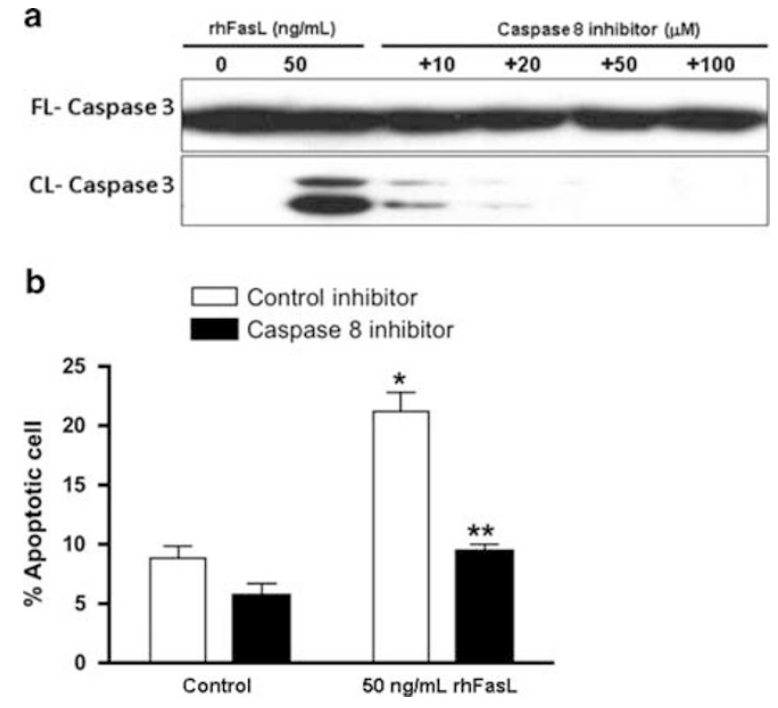

Figure 3 Inhibition of caspase-8 decreases cleaved caspase-3 and abolishes the induction of apoptosis by rhFasL in Thy-1(+) cells.

(a) Caspase-8 inhibitor was added to a final concentrations indicated for $30 \mathrm{~min}$ and then Thy-1(+) RFL- 6 were treated with $50 \mathrm{ng} / \mathrm{ml}$ rhFasL for $16 \mathrm{~h}$. Immunoblotting with anti-cleaved caspase-3 identifies caspase-3 cleavage products in Thy-1(+) RFL-6. (b) Thy-1(+) cells were pretreated with $20 \mu \mathrm{M}$ of caspase-8 inhibitor negative control or caspase-8 specific inhibitor for $30 \mathrm{~min}$ followed by $50 \mathrm{ng} / \mathrm{ml}$ rhFasL for $16 \mathrm{~h}$, and then cells were collected and stained with Annexin $\mathrm{V}$ and PI followed by flow cytometry as described in 'Methods' section. Bar graph shows average of three independent experiments of FACS analysis with FITC-Annexin V and PI. ${ }^{*} P<0.0001$ compared with control inhibitor-treated control. ${ }^{*} P<0.0001$ compared with hrFasL-treated cells pretreated with caspase-8 inhibitor. FL denotes full length; $\mathrm{CL}$ is cleaved caspase.

expressing Thy-1, we determined the extent of PARP cleavage in relation to Thy-1 expression and apoptotic stimuli. We showed that Thy-1 expression slightly increased the basal level of cleaved PARP (Figure 5a). Treatment with rhFasL at the indicated concentrations caused increased PARP cleavage in Thy-1(+) RFL-6 cells in a dose-dependent manner, whereas Thy-1(-) RFL-6 cells did not show induction of cleaved PARP under the same conditions. Likewise, treatment with staurosporine $(1 \mu \mathrm{M})$ increased the expression of cleaved PARP only in Thy-1(+) MEF fibroblasts similarly to the response to rhFasL (Figure 5b). These results indicate that expression of Thy- 1 is sufficient to sustain caspase- 3 activity leading to PARP cleavage.

\section{Thy-1-Mediated Susceptibility to Apoptosis Requires GPI Anchorage}

Many of the signaling effects of Thy-1, such as modulation of Src family kinases and focal adhesion kinase phosphorylation, depend upon its glycosylphosphatidylinositol (GPI) anchor and lipid raft localization. ${ }^{20}$ We wanted to determine whether Thy-1's GPI anchor was needed to induce susceptibility to apoptosis in lung fibroblasts. Transfection of RFL-6 cells, which are Thy-1 negative, with a human Thy-1 construct resulted in increased susceptibility to apoptosis similar to that 
a

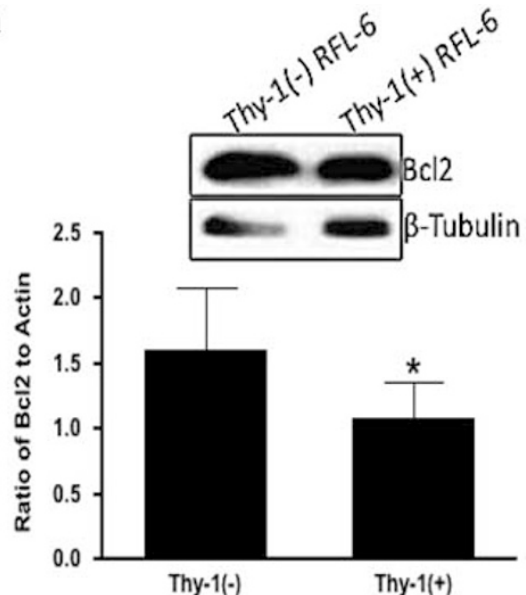

b

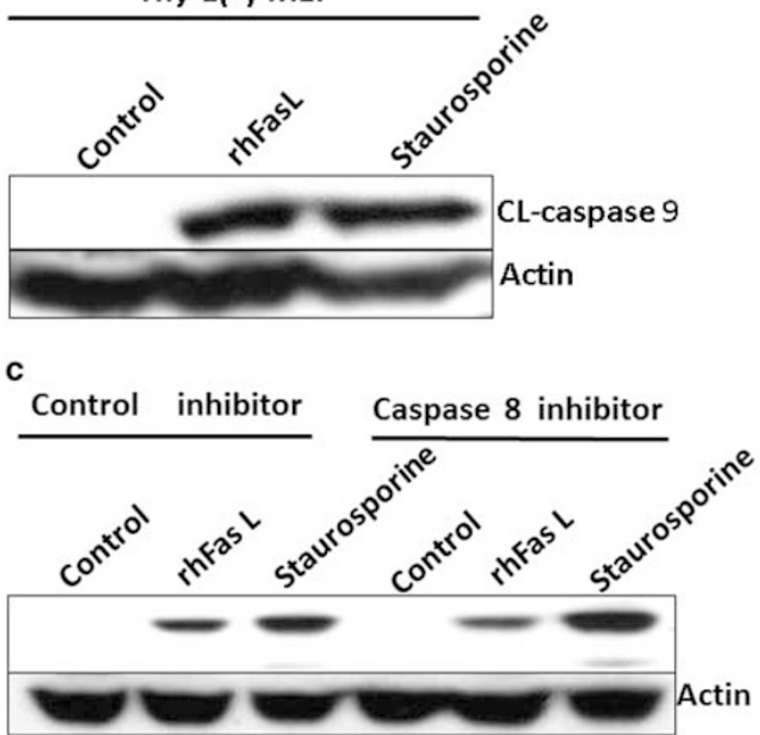

Figure 4 The effect of Thy-1 expression on the expression of anti-apoptotic proteins, Bcl2 and Bcl-xL, and the activation of caspase-9. (a) Basal level of $\mathrm{Bcl} 2$ and $\mathrm{Bcl}-\mathrm{xL}$ expression by immunoblotting in Thy- $1(-)$ and (+) RFL6 cells. ${ }^{*} P<0.05$ compared with Thy- $1(-)$ RFL-6. Thy $-1(-)$ and $(+)$ RFL-6 cells were treated with $50 \mathrm{ng} / \mathrm{ml}$ rhFasL and $1 \mu \mathrm{M}$ staurosporine and immunoblotted using anti-cleaved caspase-9. (b) Thy-1.2(+) MEFs were treated with $50 \mathrm{ng} / \mathrm{ml}$ rhFasL and staurosporine for $16 \mathrm{~h}$, cell lysates were collected for analysis of cleaved caspase-9. (c) Thy-1.2(+) MEFs were pretreated with $20 \mu \mathrm{M}$ negative control or caspase-8-specific inhibitor for $30 \mathrm{~min}$ followed by $50 \mathrm{ng} / \mathrm{ml}$ rhFasL and staurosporine for $16 \mathrm{~h}$, cell lysates were collected for analysis of cleaved caspase-9. Results are representative of three independent experiments. FL is full length; CL is cleaved caspase.

seen with the murine construct (Figure 6, gray-shaded bars). To determine whether the Thy-1-specific GPI anchor is required, we transfected RFL-6 cells with a human Thy-1hinge TR3 vector, a chimeric construct in which the GPI anchor of hThy-1 was replaced with the GPI anchor addition sequence of TRAIL receptor 3, which has previously been shown to segregate to distinct membrane microdomains. ${ }^{26}$ The expression of this chimeric Thy-1 construct failed to induce FasL-mediated apoptosis (Figure 6, black filled bars). Similar findings were seen in response to staurosporine (data not shown). These results indicate that Thy-1 requires its specific GPI anchor to induce susceptibility to apoptosis in lung fibroblasts.

\section{Thy-1 Colocalizes with Fas}

On the basis of our data so far, Thy- 1 and Fas seem to work together to induce apoptosis in lung fibroblasts. To gain insights into the mechanisms of their interaction, we examined the transcriptional effect of rhFasL on Fas protein expression in lipid rafts isolated from RFL-6 Thy-1(+) cells. We found that Thy-1 does not affect basal expression of Fas, but there is a slight increase in Fas in response to FasL stimulation in both Thy-1 - and Thy-1+ fibroblasts (Figure 7a). A specific CD95 Fas band clearly co-immunoprecipitates with mThy-1.2 in response to FasL stimulation (Figure 7b). Confocal microscopy demonstrates colocalization of Thy-1 with Fas receptor after treatment with rhFasL in 

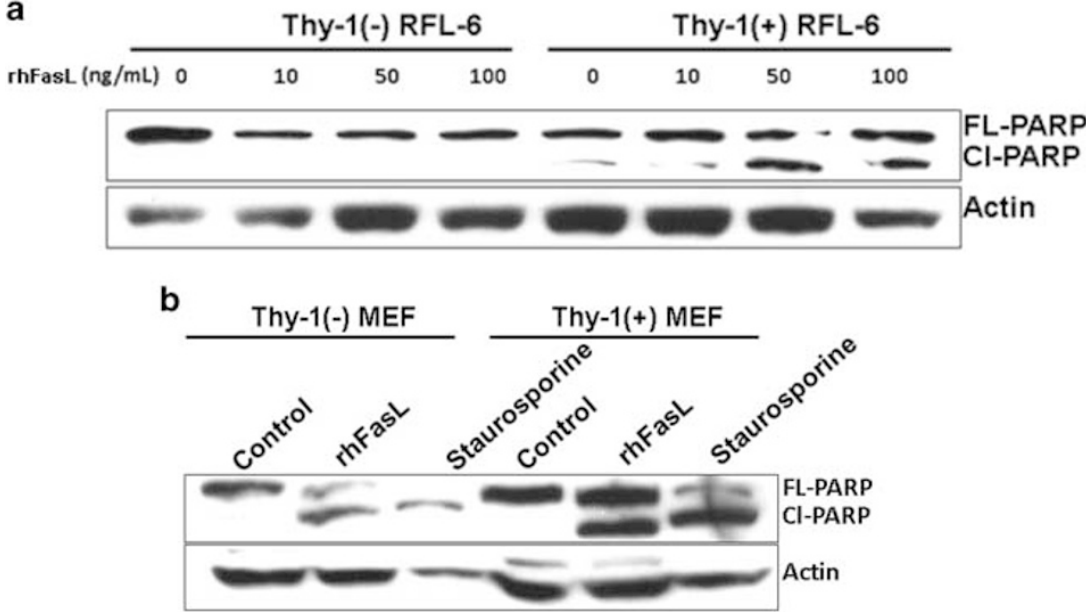

Figure 5 The effect of Thy-1 expression on PARP cleavage. (a) Thy-1(-) and (+) RFL6 cells were treated with the indicated concentration of rhFasL followed by immunoblotting using antibody against PARP. (b) Thy-1(+) MEFs were rendered quiescent and then treated with the $50 \mathrm{ng} / \mathrm{ml} \mathrm{rhFasL}$ and $1 \mu \mathrm{M}$ staurosporine for $16 \mathrm{~h}$. PARP cleavage was analyzed by anti-PARP. Three independent experiments were performed with similar results.

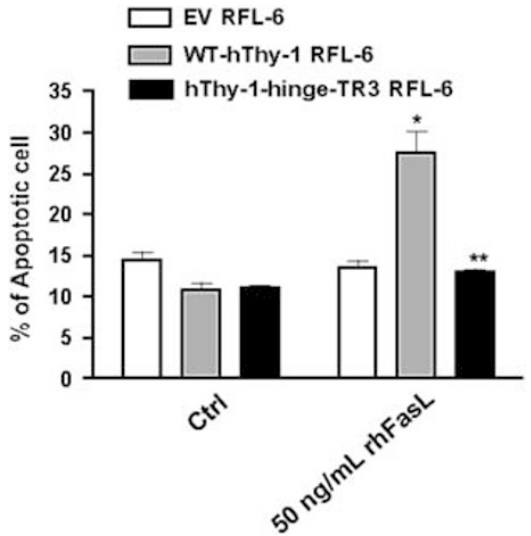

Figure 6 The GPI anchor of mouse Thy-1.2 and the Thy-1-specific GPI anchor of human Thy-1 are required for Thy-1-mediated apoptosis. Three RFL-6 cell lines (empty vector, hThy-1 and hThy-1-TR3 RFL-6) were used in this experiment were treated with $50 \mathrm{ng} / \mathrm{ml}$ rhFasL for $16 \mathrm{~h}$. Bar graphs show average of three independent experiments. Prism two-tailed $t$-test was used for statistical analysis and ${ }^{*} P<0.05$ compared with untreated control. ${ }^{*} P<0.01$ compared with rhFasL-treated Thy-1 RFL-6. FL is full length; $\mathrm{CL}$ is cleaved caspase.

RFL-6 Thy-1(+) cells (Figure 7c). Thus, our results indicate that the close interaction between Thy-1 and Fas in lipid rafts regulates fibroblast apoptosis.

\section{Thy $1^{-/-}$Mice Display Persistent Fibrotic Remodeling and Compromised Injury Resolution}

To test the relevance of the in vitro results in lung fibrosis, we examined fibrotic remodeling in $T h y 1^{-/-}$and $\mathrm{Wt}$ mice following single-dose intratracheal bleomycin instillation (a self-limited fibrotic response). Histopathological examination (H\&E staining) of tissue slides indicated persistent, non-resolving fibrosis in $T h y-1^{-/-}$mice, whereas Wt mice demonstrated restoration of normal appearing histology in most observed areas, at day 56 after bleomycin instillation. Thy $1^{-1-}$ mice were characterized by an obvious fibroproliferative response, enhanced cellularity, alveolar septal thickening, architectural distortion, and severe alveolar destruction (data not shown). There was a highly significant increase in lung collagen deposition, as determined by increased trichrome staining (Figure $8 \mathrm{a}$ and $\mathrm{b}$ ) and western blotting (Figure 8c) in Thy $1^{-1-}$ lungs relative to Wt lungs. These results demonstrated that mice lacking Thy-1 failed to resolve lung fibrosis, suggesting that Thy-1 is extremely important for normal tissue remodeling following bleomycininduced lung injury.

\section{Decreased Fibroblast Apoptosis Associated with Myofibroblast Accumulation in Mice Lacking Thy-1}

Immunohistochemical detection of cleaved caspase- 3 and aSMA (Figure 9a) was performed to assess myofibroblast apoptosis in Thy $1^{-/-} v s \mathrm{Wt}$ mice after bleomycin instillation. At 28 days after bleomycin, myofibroblasts appeared throughout the lungs of Thy $1^{-1-}$ and Wt mice. Quantitative data showed that $36.8 \pm 5.3$ vs $30.4 \pm 6.3 \%$ cells/hpf stained positive for aSMA in $T h y 1^{-1-}$ and Wt mice, respectively. However, the number of aSMA-stained cells positive for cleaved caspase-3 (CL-caspase3(+)/aSMA(+) apoptotic myofibroblasts) was significantly less in $T h y 1^{-1-}$ mice than in $\mathrm{Wt}$ mice (Figure 9b). At day 56, there remained aSMA(+) myofibroblasts along with persistently abnormal lung architecture in Thy $1^{-1-}$ mice, whereas $\mathrm{Wt}$ mice demonstrated disappearance of aSMA staining in most observed areas.

\section{DISCUSSION}

This study provides new evidence that expression of Thy- 1 in lipid rafts and colocalization with Fas promote lung fibroblast susceptibility to apoptosis, whereas fibroblasts lacking Thy-1 
a

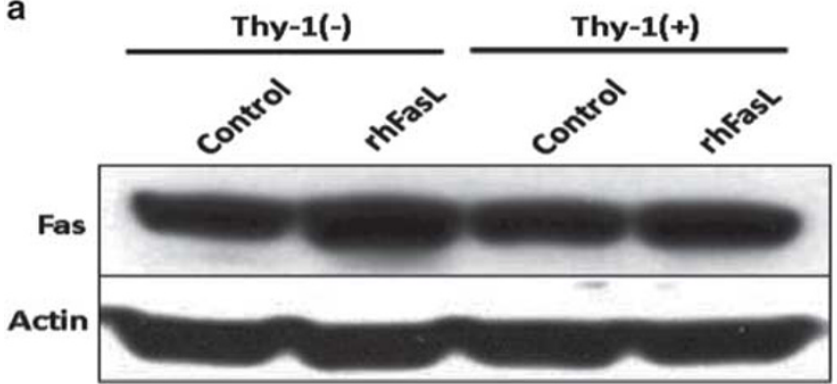

c
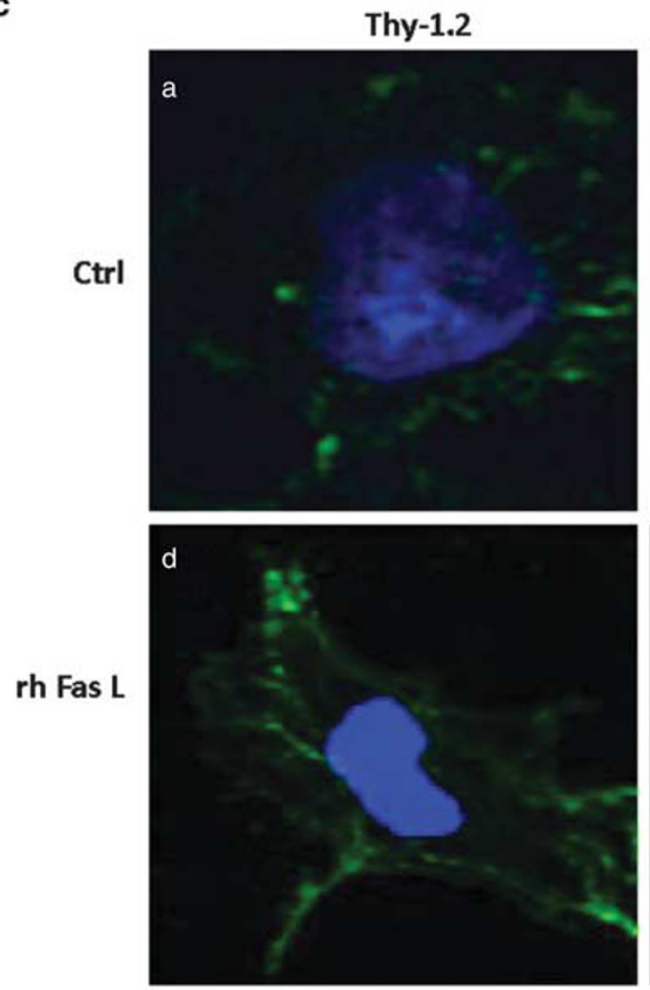

b

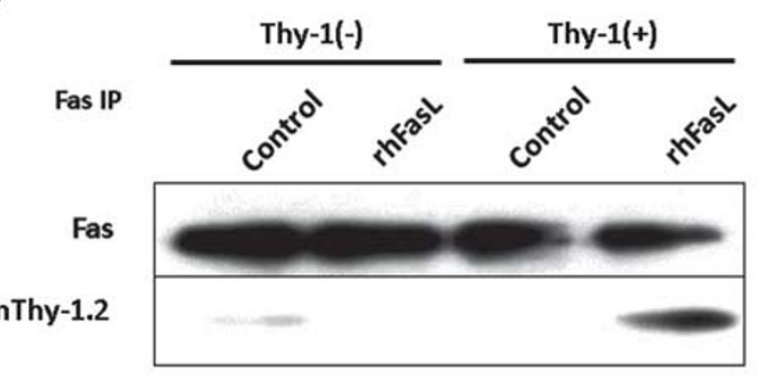

Fas
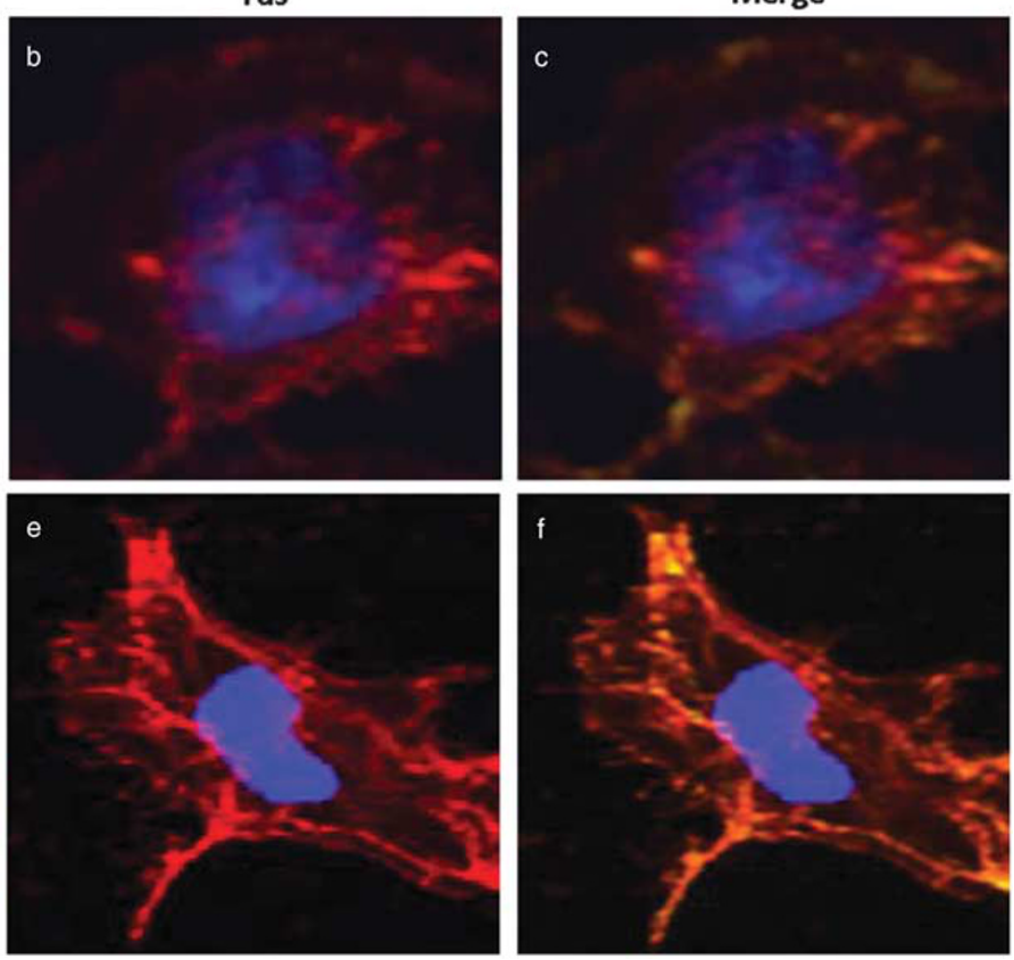

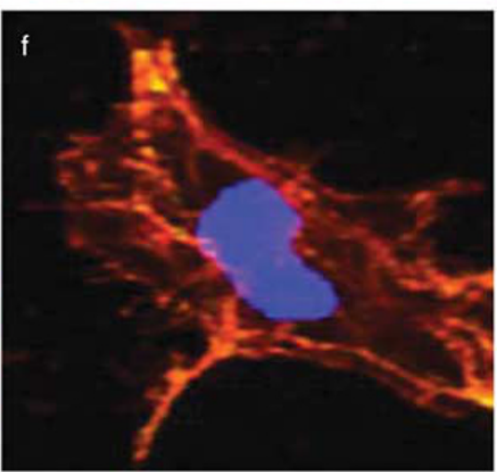

Figure 7 Interaction of Thy-1 with Fas-mediated signaling pathway and lipid raft integrity are required for the activation of caspase-3. (a) Membrane fractionation and immunoisolation of lipid rafts was performed as described in 'Methods' section. Total cell lysates prepared from Thy-1.2(+) RFL-6 were used for IP with anti-Fas or normal mouse IgM as described in experimental procedures. Proteins from the immunoprecipitates were detected by western blotting using anti-mouse Thy-1.2 antibody (upper panel) or anti-Fas antibody (lower panel). (b) Cell lysates were collected from Thy-1.2(-) and Thy-1.2(+) RFL-6 followed by immunoblotting. (c) Cells were cultured on coverslips as shown in 'Materials and Methods' section and colocalization of Thy-1 with Fas in Thy-1(+) RFL-6 was performed. Staining shows Thy-1.2 (a and $\mathbf{d}$, green) and Fas (b and e, red) associated with the plasma membrane. Yellow color indicates colocalization of Thy-1.2 and Fas after apoptosis induction by $50 \mathrm{ng} / \mathrm{ml} \mathrm{rhFasL}$ (c and f).

are resistant to apoptosis, via caspase-9- and caspase-8dependent pathways. Activation of caspases for apoptosis requires the Thy-1-specific GPI anchor. These findings suggest that localization of Thy-1 to specific lipid raft microdomains places Thy- 1 in proximity to the downstream signaling molecules that regulate apoptosis (Figure 10). Our in vivo study demonstrates that Thy-1 is essential for disappearance of $\mathrm{aSMA}(+)$ fibroblasts and resolution of fibrosis following bleomycin-induced lung injury in the single-dose model, indicating that absence of Thy-1 was associated with an apoptosis-resistant myofibroblast phenotype, and persistence/progression of lung fibrosis.
Apoptosis is typically executed by caspase activation and regulated by the Bcl-2 protein family. It is thought that Bcl-2 and Bcl-xL inhibit FasL-induced apoptosis because they prevent the release of cytochrome $c$ from mitochondria and subsequent activation of caspase-9; however, inhibition of apoptosis by Bcl-2 affects other pathways in addition to cytochrome $c$, caspase-9, and its activator Apaf-1. ${ }^{27}$ The association between Bcl-2 family members and development of pulmonary fibrosis has been reviewed elsewhere. ${ }^{28}$ In this study, the expression of Bcl-2 and Bcl-xL was decreased in response to Thy-1 expression, and could lead to caspase cascade activation of apoptosis pathways from caspase-9 to 
a

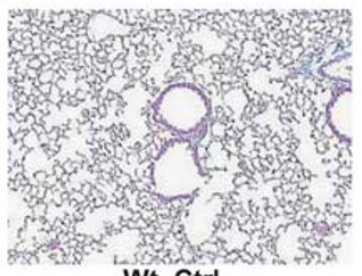

Wt, Ctrl

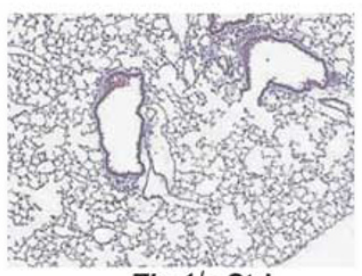

Thy $1^{-1}$, Ctrl

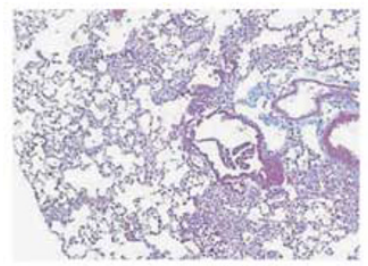

Wt, Bleo d28

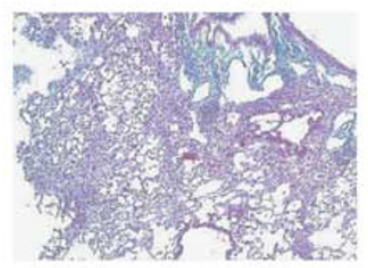

Thy ${ }^{\%}$, Bleo d28

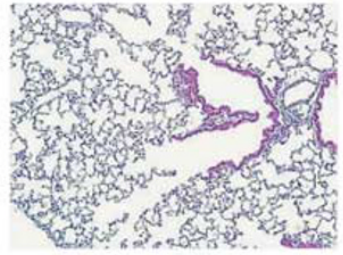

Wt, Bleo d56

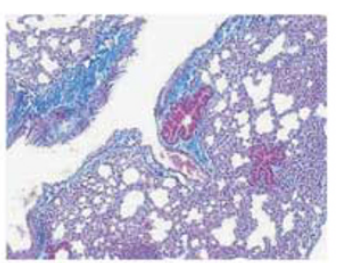

Thy ${ }^{\%}$, Bleo d56

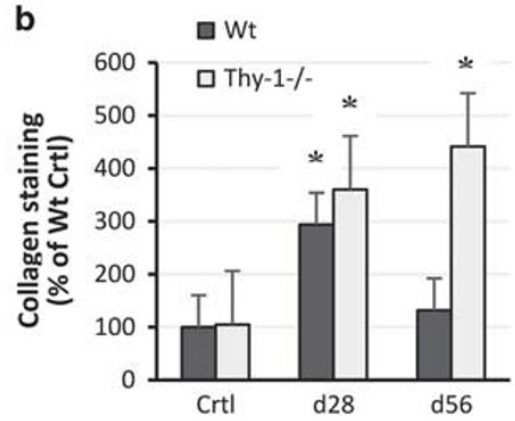

Bleomycin instillation

C

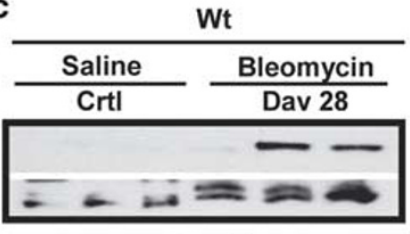

Thy $1^{\text {1- }}$

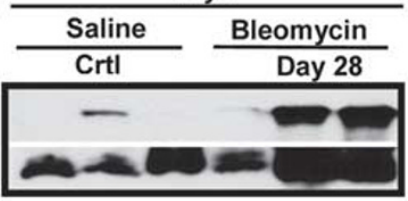

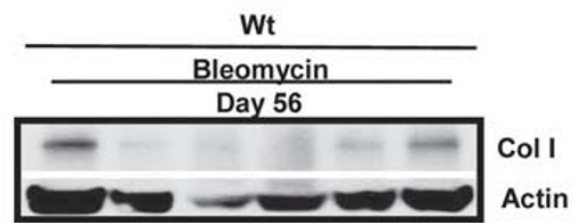

Thy t. $^{\text {- }}$

Bleomycin

Day 56

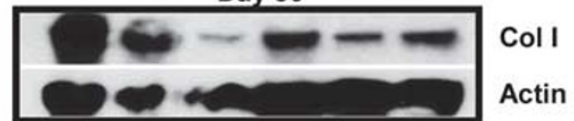

Figure 8 Failure of resolution of bleomycin-induced lung fibrosis in Thy $1^{-/-}$mice, leading to persistent extracellular matrix accumulation. Mice were instilled with bleomycin $(5 \mathrm{U} / \mathrm{kg}$ ) by orotracheal MicroSprayer MS-IA-1C (Penn-Century). The lung tissue was collected at each time point, fixed (10\% formalin), embedded (paraffin), and stained with Masson's Trichrome after intratracheal instillation of bleomycin, revealing collagen accumulation with persistently abnormal lung architecture in Thy $1^{-1-}$ mice at day 56, whereas Wt mice demonstrated restoration of normal appearing histology in most observed areas. (a) Masson's Trichrome stain, $\times 10$. (b) Quantification of collagen staining (\% increase over Wt saline). (c) Immunoblots of Col I, in Wt and Thy $1^{-1-}$ mice over time after bleomycin instillation. * $P<0.05$ when compared with Wt control group.

effector caspase-3 and PARP. Considering the possibility of crosstalk between the extrinsic and intrinsic pathways in response to Fas, ${ }^{29-31}$ we also measured the activation of caspase-8, a downstream effector of the death receptormediated extrinsic apoptotic pathway. Notably, cleavage of caspase- 8 and -3 were significantly increased after rhFasL and staurosporine treatment in Thy- $1(+)$ cells. Caspase- 8 inhibition reduced rhFasL-mediated apoptosis, confirming that caspase- 8 cleavage is upstream of caspase- 3 cleavage, indicating activation of the extrinsic pathway dependent on Thy- 1 . However, caspase-8 inhibition did not alter the cleavage of caspase- 9 , suggesting that the caspase- 9 activation is likely to be independent of the caspase-8-mediated extrinsic apoptotic pathway. Therefore, the data here demonstrate that Thy-1 mediates apoptotic signaling via both caspase-9- and caspase8-dependent pathways.

The presence of the GPI anchor affects the conformation and subcellular localization of Thy- 1 . To determine whether the GPI anchor is required for Thy-1-mediated apoptosis, we used a construct in which the GPI anchor of CD90.2 was replaced with a sequence from the transmembrane domain of CD8 (Thy-1-CD8), which is known to lack the inhibitory effects of Wt Thy-1 on neurite outgrowth. ${ }^{20,32}$ Thy-1 lacking the GPI anchor does not localize to the same membrane microdomains as Wt Thy-1, suggesting the GPI anchor is necessary for localization of Thy- 1 to specific lipid raft microdomains, ${ }^{32}$ however, mutant chimeric Thy- 1 proteins are insufficiently specific to rule out other structural effects unrelated to specific GPI function. Expression of Thy-1-CD8 in Thy-1(- ) cells did not increase rhFasL-mediated apoptosis, unlike expression of Wt Thy-1, suggesting that the GPI anchor and lipid raft localization of Thy- 1 is necessary for Thy-1-mediated apoptotic signaling.

To determine whether the GPI anchor specific to Thy- 1 is required, we replaced the GPI anchor of human Thy-1 with the GPI addition sequence of TRAIL receptor 3 and we transfected RFL-6 cells with human Thy-1-hinge-TR3. ${ }^{22}$ The specific GPI sequences for Thy-1 and TRAILR3 have 
a

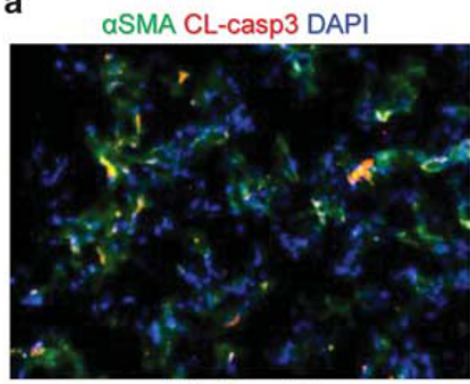

Wt, Bleo d28

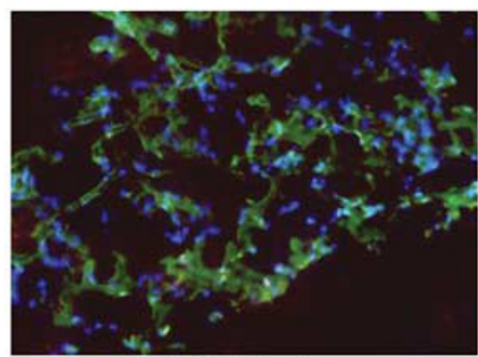

Thy $1^{1 \%}$, Bleo d28

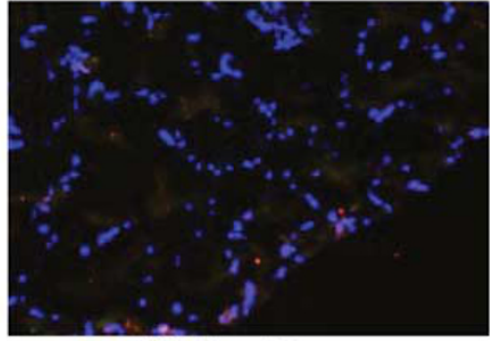

Wt, Bleo d56

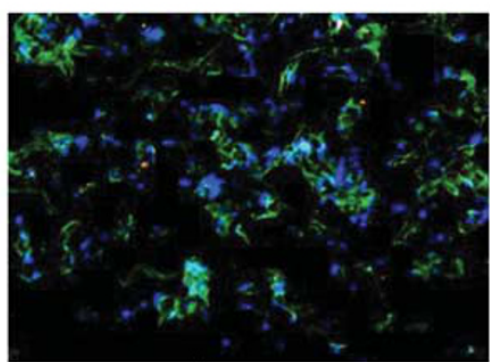

Thy $1^{-1}$, Bleo d56

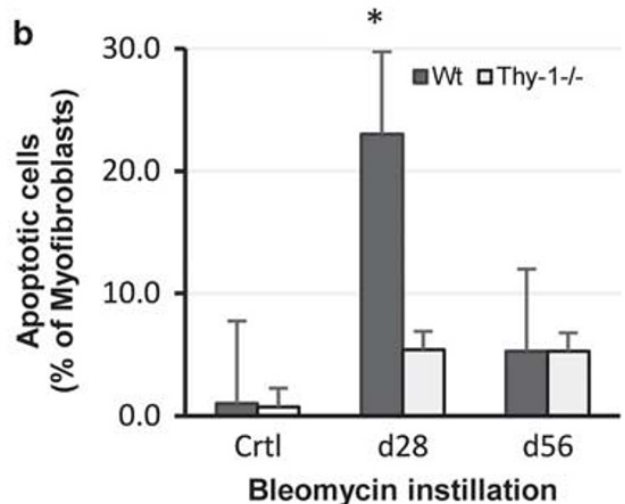

Figure 9 Decreased apoptosis of lung myofibroblasts in $T h y 1^{-1-}$ mice and accumulation in the fibrotic resolution phase. Lung tissue was collected at indicated time points. Five micrometer OCT-embedded frozen tissue sections were fixed with 4\% PFA and processed for double immunostaining of aSMA (myofibroblasts, green) and CL-Casp3 (apoptosis, red). Nuclei were counterstained with DAPI (blue). Wt mice displayed strong apoptotic signaling in aSMA (+) cells at day 28. Thy $1^{-1-}$ mice had persistent aSMA (+) cells throughout the lungs. (a) Double immunostaining of aSMA (green) and CL-Casp3 (red). (b) Apoptotic cells as \% of total aSMA(+) cells. One-way ANOVA and Newman-Keuls multiple comparisons tests were used to calculate statistical significance. ${ }^{*} P<0.05$ when compared with Wt control group.

previously been shown to segregate to distinct membrane microdomains. ${ }^{33}$ The results showed that the expression of Thy-1-hinge-TR3 rendered cells insensitive to rhFasLmediated apoptosis compared with Wt hThy-1 expression, confirming that the Thy-1-specific GPI anchor and its specific membrane subdomain localization is required for its proapoptotic effects.

Lipid rafts are tightly packed, liquid-ordered phase microdomains in plasma membranes and participate in various cellular functions, including cell survival and cell death. ${ }^{34,35}$ Thy- 1 is localized in specific lipid raft subdomains, and its localization is important to its biological functions. Fas-mediated apoptosis involves translocation of Fas and downstream signaling molecules into lipid rafts, a process that can be pharmacologically modulated. Engagement of FasL leads to trimerization of Fas and clustering of its intracellular death domain, which in turn leads to the recruitment of the cytoplasmic Fas-associated death domain. The cascade of caspases is then set off and this ultimately leads to cell death. In Thy-1(+) cells, rhFasL treatment induced the colocalization of Thy-1 with Fas as demonstrated by confocal microscopy.

The role of Thy-1 for fibroblast apoptosis in tissue remodeling was examined in Thy $1^{-/-}$mice $v s \mathrm{Wt}$ mice after bleomycin instillation. In vivo data revealed persistence of both myofibroblast and collagen accumulation with abnormal lung architecture in $\mathrm{Thy}^{-1-}$ mice, whereas Wt mice showed normal or near-normal alveolar structure at day 56. Thy-1 loss could contribute, at least in part, to fibroblast resistance to Fas-induced apoptosis seen in pathological fibrosis and aging lungs. ${ }^{21,36,37}$ Several recent studies of organ fibrosis strongly support this role for Thy-1 in myofibroblast apoptosis and tissue remodeling. Thy- $1 / \beta 3$ integrin-induced apoptosis of dermal fibroblasts is mediated by upregulation of FasL expression. ${ }^{13}$ Another study has reported that Thy- 1 upregulates FasL expression via Src family kinases. ${ }^{38}$ Thy- $1 / \beta 3$ integrin interaction also triggers tyrosine phosphorylation of focal adhesion proteins promoting focal adhesion formation and cell attachment. ${ }^{39}$ Relevance of this process to human fibrotic lung disease was highlighted by a recent study describing Thy-1's role as a molecular mechanosensor. In that study, normal human fibroblasts were shown to undergo apoptosis when shifted from a physiologically stiff $(18.7 \mathrm{kPa})$ to a soft $(1.8 \mathrm{kPa})$ extracellular matrix substrate; however, Thy-1(-) myofibroblasts from lungs of individuals with idiopathic pulmonary fibrosis were resistant to apoptosis induced by decreased matrix stiffness. ${ }^{40}$ These studies indicate that Thy-1 functions via its subcellular localization or molecular interactions to facilitate cellular susceptibility to apoptosis. Moreover, there is the possibility that additional molecules may modify Thy- $1 / \beta 3$ integrin interaction. ${ }^{41}$

An additional important finding of this study is that Thy $1^{-/-}$mice have persistent, non-resolving fibrosis following single-dose intratracheal bleomycin, unlike the 


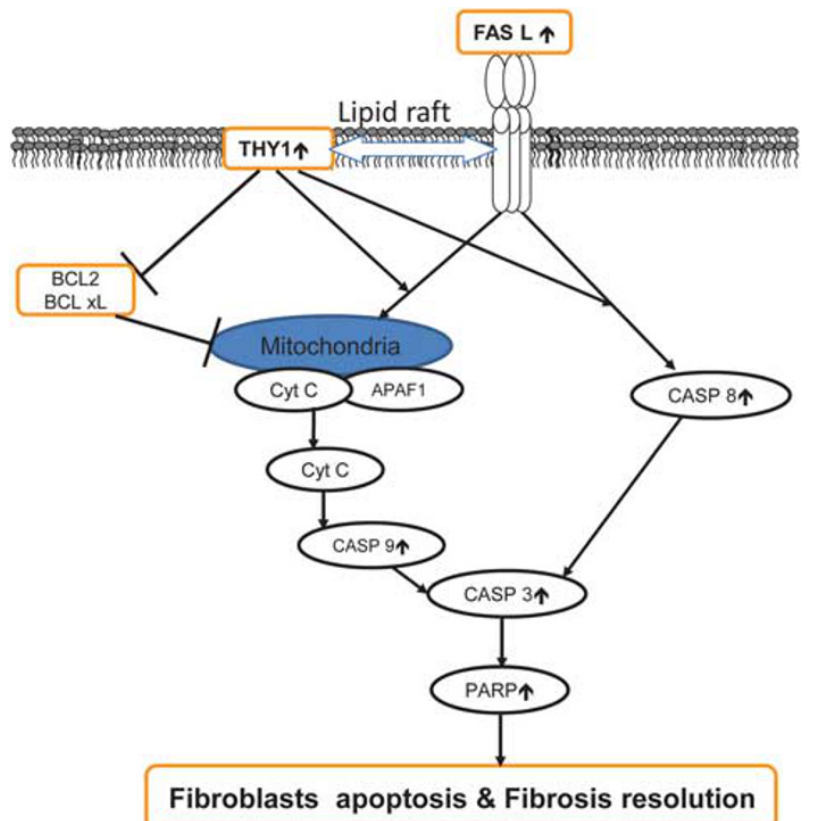

Figure 10 The model of Thy-1-mediated apoptosis pathway induced by FasL. Stimulated Thy- 1 increases in the activation of caspase- $8,-3$, and -9 followed by PARP activation. The action of caspase- 9 activation is likely to be independent of caspase-8- and 3-mediated apoptotic pathway as indicated in the figure. Caspase- 8 inhibition can reduce caspase- 9 activation mediated by FasL but not by staurosporine, indicating that the anti-apoptotic proteins, such as $\mathrm{BCl}-2$ and $\mathrm{BCl}-\mathrm{xL}$, are involved. The expression of $\mathrm{BCl}-2$ and $\mathrm{BCl}-\mathrm{xL}$ is decreased Thy-1(+) cells. Decreased levels of $\mathrm{BCl}-2$ and $\mathrm{BCl}-\mathrm{xL}$ will induce activation of the mitochondrial pathway.

spontaneously resolving fibrosis seen in $\mathrm{Wt}$ mice. The myofibroblast resistance to apoptosis associated with progressive fibrosis is more characteristic of progressive fibrotic disorders in humans, such as idiopathic pulmonary fibrosis. Therefore, the Thy1 $1^{-1-}$ model may be a more relevant preclinical model for testing antifibrotic therapeutics.

In summary, this study characterized the mechanism of Thy-1-mediated apoptosis in lung (myo)fibroblasts, critical effector cells in fibrosis resolution. This modulation of Thy-1 was dependent on lipid raft integrity and the Thy-1-specific GPI anchor. The in vivo results strongly support a regulatory role for Thy-1 in initiation of (myo)fibroblast apoptosis that heralds the termination of the reparative response to lung injury. Thy-1-mediated pro-apoptotic effects could either halt the progression or speed the resolution of lung fibrosis via the pro-apoptotic effects. Therefore, it is possible that Thy-1 reexpression through targeted gene therapy or molecular mimicry could restore apoptosis susceptibility in apoptosisresistant lesional fibroblasts in pulmonary fibrosis and other fibrotic diseases.

\section{ACKNOWLEDGMENTS}

We are grateful for the support of the National Heart, Lung and Blood Institute via NIH grant R01 HL111169.

\section{DISCLOSURE/CONFLICT OF INTEREST}

The authors declare no conflict of interest.

1. Waring $\mathrm{P}$, Mullbacher A. Cell death induced by the Fas/Fas ligand pathway and its role in pathology. Immunol Cell Biol 1999;77: 312-317.

2. Lazebnik YA, Kaufmann SH, Desnoyers S, et al. Cleavage of poly(ADPribose) polymerase by a proteinase with properties like ICE. Nature 1994;371:346-347.

3. Fattman CL. Apoptosis in pulmonary fibrosis: too much or not enough? Antioxid Redox Signal 2008;10:379-385.

4. Maher TM, Evans IC, Bottoms SE, et al. Diminished prostaglandin E2 contributes to the apoptosis paradox in idiopathic pulmonary fibrosis. Am J Respir Crit Care Med 2010;182:73-82.

5. Thannickal VJ, Horowitz JC. Evolving concepts of apoptosis in idiopathic pulmonary fibrosis. Proc Am Thorac Soc 2006;3:350-356.

6. Moodley YP, Caterina P, Scaffidi AK, et al. Comparison of the morphological and biochemical changes in normal human lung fibroblasts and fibroblasts derived from lungs of patients with idiopathic pulmonary fibrosis during FasL-induced apoptosis. J Pathol 2004;202:486-495.

7. Glasser SW, Hagood JS, Wong S, et al. Mechanisms of lung fibrosis resolution. Am J Pathol 2016;186:1066-1077.

8. Wynes MW, Edelman BL, Kostyk AG, et al. Increased cell surface Fas expression is necessary and sufficient to sensitize lung fibroblasts to Fas ligation-induced apoptosis: implications for fibroblast accumulation in idiopathic pulmonary fibrosis. J Immunol 2011;187:527-537.

9. Redente EF, Keith RC, Janssen W, et al. Tumor necrosis factor-alpha accelerates the resolution of established pulmonary fibrosis in mice by targeting profibrotic lung macrophages. Am J Respir Cell Mol Biol 2014;50:825-837.

10. Wallach-Dayan SB, Elkayam L, Golan-Gerstl R, et al. Cutting edge: FasL (+) immune cells promote resolution of fibrosis. J Autoimmun 2015;59: 67-76.

11. Cheng $B Q$, Jiang $Y$, Zhu $Q$, et al. Wnt/beta-catenin aids in regulating the proliferation of hepG2 cells mediated by thy-1. Genet Mol Res 2014;13:5115-5127.

12. Qiu W, Zhou J, Zhu G, et al. Sublytic C5b-9 triggers glomerular mesangial cell apoptosis via XAF1 gene activation mediated by $\mathrm{p300}$ dependent IRF-1 acetylation. Cell Death Dis 2014;5:e1176.

13. Schmidt $M$, Gutknecht $D$, Anastassiadis $K$, et al. Thy- $1 / \beta 3$ integrin interaction-induced apoptosis of dermal fibroblasts is mediated by up-regulation of FasL expression. J Invest Dermatol 2016;136:526-529.

14. Rege TA, Hagood JS. Thy- 1 as a regulator of cell-cell and cell-matrix interactions in axon regeneration, apoptosis, adhesion, migration, cancer, and fibrosis. FASEB J 2006;20:1045-1054.

15. Sanders YY, Kumbla P, Hagood JS. Enhanced myofibroblastic differentiation and survival in Thy-1(-) lung fibroblasts. Am J Respir Cell Mol Biol 2007;36:226-235.

16. Sanders $Y Y$, Pardo A, Selman M, et al. Thy-1 promoter hypermethylation: a novel epigenetic pathogenic mechanism in pulmonary fibrosis. Am J Respir Cell Mol Biol 2008;39:610-618.

17. Zhou Y, Hagood JS, Murphy-Ullrich JE. Thy-1 expression regulates the ability of rat lung fibroblasts to activate transforming growth factorbeta in response to fibrogenic stimuli. Am J Pathol 2004;165:659-669.

18. Barlow JZ, Kelley KA, Bozdagi O, et al. Testing the role of the cellsurface molecule Thy-1 in regeneration and plasticity of connectivity in the CNS. Neuroscience 2002;111:837-852.

19. Barker TH, Pallero MA, MacEwen MW, et al. Thrombospondin-1induced focal adhesion disassembly in fibroblasts requires Thy-1 surface expression, lipid raft integrity, and Src activation. J Biol Chem 2004;279:23510-23516.

20. Rege TA, Pallero MA, Gomez C, et al. Thy-1, via its GPI anchor, modulates Src family kinase and focal adhesion kinase phosphorylation and subcellular localization, and fibroblast migration, in response to thrombospondin-1/hep I. Exp Cell Res 2006;312: 3752-3767.

21. Hagood JS, Miller PJ, Lasky JA, et al. Differential expression of plateletderived growth factor-alpha receptor by Thy-1(-) and Thy-1(+) lung fibroblasts. Am J Physiol 1999;277:L218-L224.

22. Bradley JE, Chan JM, Hagood JS. Effect of the GPI anchor of human Thy- 1 on antibody recognition and function. Lab Invest 2013;93: 365-374. 
23. Barker TH, Grenett HE, MacEwen MW, et al. Thy-1 regulates fibroblast focal adhesions, cytoskeletal organization and migration through modulation of p190 RhoGAP and Rho GTPase activity. Exp Cell Res 2004:295:488-496.

24. Ostrom RS, Gregorian C, Drenan RM, et al. Receptor number and caveolar co-localization determine receptor coupling efficiency to adenylyl cyclase. J Biol Chem 2001;276:42063-42069.

25. Harlow $\mathrm{E}$, Lane D. Mounting samples in gelvatol or mowiol. CSH Protoc 2006;2006

26. Degli-Esposti MA, Smolak PJ, Walczak $\mathrm{H}$, et al. Cloning and characterization of TRAIL-R3, a novel member of the emerging TRAIL receptor family. J Exp Med 1997;186:1165-1170.

27. Marsden VS, O'Connor L, O'Reilly LA, et al. Apoptosis initiated by Bcl-2regulated caspase activation independently of the cytochrome c/Apaf1/caspase-9 apoptosome. Nature 2002;419:634-637.

28. Safaeian L, Abed A, Vaseghi G. The role of $\mathrm{Bcl}-2$ family proteins in pulmonary fibrosis. Eur J Pharmacol 2014;15:281-289.

29. Jost PJ, Grabow S, Gray D, et al. XIAP discriminates between type I and type II FAS-induced apoptosis. Nature 2009:460:1035-1039.

30. Roy S, Nicholson DW. Cross-talk in cell death signaling. J Exp Med 2000;192:21-26.

31. Scaffidi C, Fulda S, Srinivasan A, et al. Two CD95 (APO-1/Fas) signaling pathways. EMBO J 1998;17:1675-1687.

32. Tiveron MC, Nosten-Bertrand $\mathrm{M}$, Jani $\mathrm{H}$, et al. The mode of anchorage to the cell surface determines both the function and the membrane location of Thy-1 glycoprotein. J Cell Sci 1994;107:1783-1796.
33. Legler DF, Doucey MA, Schneider $P$, et al. Differential insertion of GPI-anchored GFPs into lipid rafts of live cells. FASEB J 2005;19:73-75.

34. George KS, Wu S. Lipid raft: a floating island of death or survival. Toxicol Appl Pharmacol 2012;259:311-319.

35. Mollinedo F, Gajate C. Fas/CD95 death receptor and lipid rafts: new targets for apoptosis-directed cancer therapy. Drug Resist Updat 2006;9:51-73.

36. Kukulansky T, Abramovitch S, Hollander N. Cleavage of the glycosylphosphatidylinositol anchor affects the reactivity of thy-1 with antibodies. J Immunol 1999;162:5993-5997.

37. Huang SK, Scruggs AM, Donaghy J, et al. Histone modifications are responsible for decreased Fas expression and apoptosis resistance in fibrotic lung fibroblasts. Cell Death Dis 2013;4:e621.

38. Cohen PY, Breuer R, Wallach-Dayan SB. Thy1 up-regulates FasL expression in lung myofibroblasts via Src family kinases. Am J Respir Cell Mol Biol 2009;40:231-238.

39. Avalos $A M$, Valdivia $A D$, Munoz $N$, et al. Neuronal Thy- 1 induces astrocyte adhesion by engaging syndecan-4 in a cooperative interaction with alphavbeta3 integrin that activates PKCalpha and RhoA. J Cell Sci 2009;122:3462-3471.

40. Fiore VF, Strane PW, Bryksin AV, et al. Conformational coupling of integrin and Thy- 1 regulates Fyn priming and fibroblast mechanotransduction. J Cell Biol 2015;211:173-190.

41. Itami S, Tamotsu S, Sakai A, et al. The roles of THY1 and integrin beta3 in cell adhesion during theca cell layer formation and the effect of follicle-stimulating hormone on THY1 and integrin beta3 localization in mouse ovarian follicles. Biol Reprod 2011;84:986-995. 